Journal of Advanced Research in Fluid Mechanics and Thermal Sciences

Journal homepage: www.akademiabaru.com/arfmts.html ISSN: 2289-7879

\title{
Effects of Suction/Injection on Stagnation Point Flow over a Nonlinearly Stretching/Shrinking Sheet in a Carbon Nanotubes
}

\author{
Nur Hazirah Adilla Norzawary ${ }^{1,{ }^{*}}$, Norfifah Bachok ${ }^{1,2}$, Fadzilah Md Ali, ${ }^{1,2}$ \\ Institute for Mathematical Research, Universiti Putra Malaysia, 43400, UPM Serdang, Selangor, Malaysia \\ Department of Mathematics, Faculty of Science, Universiti Putra Malaysia, 43400, UPM Serdang, Malaysia
}

\section{ARTICLE INFO}

Article history:

Received 29 April 2020

Received in revised form 1 August 2020

Accepted 9 August 2020

Available online 8 October 2020

Keywords:

Stagnation point flow; Nonlinear;

Stretching/shrinking; Carbon Nanotubes;

Suction/injection; Dual Solutions

\section{ABSTRACT}

This research will explore the issue of stagnation point flow in carbon nanotubes with suction/injection impacts by a nonlinear stretching/shrinking sheet. By practising a similarity transformation, the governing partial differential equations (PDEs) are converted to a scheme of nonlinear ordinary differential equations (ODEs). Then, settled numerically with applying a bvp4c solver in Matlab. Two types of carbon nanotubes (CNTs) are used which are SWCNTs (single-walled) and MWCNTs (multiwalled) and the base fluid used is water. In the form of graphs, the impact of the velocity, temperature, skin friction and numbers of Nusselts parameter is researched and displayed and interpreted physically. It is found that if only suction rises, the range of solutions will increase.

\section{Introduction}

The flow due to stretching sheet is a major issue in fluid mechanics because of its enormous applications in many assembly types in sector, for instance, extraction of polymer sheets, drawing of wire, paper development and many more. The first investigation on the boundary layer flow through a linear stretching sheet was via Crane [1]. Meanwhile, Lok et al., [2] analysed stagnation point flow by a linear shrinking surface with MHD. After that, many researchers interested to extend their work [3-7]. Most of the literature available is about studying the boundary layer flow considering linear surface. We should mention that stretching isn't always linear, several authors have also researched the issue of nonlinear stretching sheet.

Vajravelu [8] studied heat transfer for nonlinear stretching surface. Cortell [9] continued the paper by [8] where two distinct forms of thermal boundary conditions are considered on the sheet.

\footnotetext{
* Corresponding author.

E-mail address: nurhazirah0929@gmail.com
}

https://doi.org/10.37934/arfmts.76.1.3038 
Prasad et al., [10] studied the heat transfer of convection by a nonlinear stretching surface with changeable fluid characteristics. Besides paper mentioned, there is also many other researchers who interested to study on nonlinear stretching/shrinking sheet [11-17].

As many study related to nanofluid, and also due to its electrical and mechanical characteristics, CNTs also demonstrate outstanding outcomes. Thus, Choi et al., [18] researched oil-based CNTs' heat conductivity. CNTs is an allotrope of carbon, tube-shaped material and made of carbon. They consist of SWCNT and MWCNTs. Compared to the various nanoparticles with a similar fraction of volume [19-20], CNTs give a greater thermal property. This will enhance both heat transfer of convection and base fluids' thermic conductivity. Since then, numerous researchers come across the benefits of CNTs and investigated various boundary layer problem on CNTs [21-26].

Despite the literature that is often quoted, no study has been made for stagnation point flow by a nonlinear stretching/shrinking surface with CNTs alongside suction/injection. To do so, we extend Malvandi et al., [27] paper which they studied on stagnation point flow of porous nonlinear stretching/shrinking surface.

\section{Methodology}

Consider an incompressible steady flow concerning stretching/shrinking sheet in CNTs alongside suction/injection. The velocity of free stream and velocity of sheet are presumed to differ nonlinearly from a steady point of stagnation, which complement to $U_{w}(x)=a x^{n}$ and $U_{\infty}(x)=b x^{n}$, respectively, where $a$ and $b$ are constants. Both SWCNTs and MWCNTs are used with water base fluid. The boundary layer equations can be addressed as follows [28]

$\frac{\partial u}{\partial x}+\frac{\partial v}{\partial y}=0$

$u \frac{\partial u}{\partial x}+v \frac{\partial u}{\partial y}=U_{\infty} \frac{d U_{\infty}}{d x}+\frac{\mu_{n f}}{\rho_{n f}} \frac{\partial^{2} u}{\partial y^{2}}$

$u \frac{\partial T}{\partial x}+v \frac{\partial T}{\partial y}=\alpha_{n f} \frac{\partial^{2} T}{\partial y^{2}}$

and the boundary conditions are

$$
\begin{aligned}
& u=U_{w}, v=V_{w}, T=T_{w} \text { at } y=0 \\
& u \rightarrow U_{\infty}, T \rightarrow T_{\infty} \text { as } y \rightarrow \infty
\end{aligned}
$$

It should be mention that $V_{w}$ is the mass transfer velocity, and $\mu_{n f}, \alpha_{n f}, \rho_{n f}$ are the viscosity, thermal diffusivity and density of the nanofluid, respectively, that Oztop and Abu-Nada [29] offer

$$
\alpha_{n f}=\frac{k_{n f}}{\left(\rho C_{p}\right)_{n f}}, \mu_{n f}=\frac{\mu_{f}}{(1-\varphi)^{2.5}}, \rho_{n f}=(1-\varphi) \rho_{f}+\varphi \rho_{C N T},
$$




$$
\left(\rho C_{p}\right)_{n f}=(1-\varphi)\left(\rho C_{p}\right)_{f}+\varphi\left(\rho C_{p}\right)_{C N T}, \quad \frac{k_{n f}}{k_{f}}=\frac{1-\varphi+2 \varphi \frac{k_{C N T}}{{ }_{k_{C N T}-k_{f}} \ln \frac{{ }{ }_{C N T}+k_{f}}{2 k_{f}}}}{1-\varphi+2 \varphi \frac{k_{f}}{k_{C N T}-k_{f}} \ln \frac{{ }^{k_{C N T}+k_{f}}}{{ }^{2} k_{f}}}
$$

where $\varphi$ is the CNTs volume fraction, $\left(\rho C_{p}\right)_{n f}$ and $k_{n f}$ are the capacity of heat and thermal conductivity of nanofluid, while $\left(\rho C_{p}\right)_{C N T}, k_{C N T}$ and $\rho_{C N T}$ are the capacity of heat, thermal conductivity and density of CNTs, respectively, and $\rho_{f}$ and $k_{f}$ are the density and thermal conductivity of the fluid. The use of the term for $k_{n f} / k_{f}$ were taken from Xue [30] where the Maxwell's theory model considers the effects of CNTs space distribution on thermal conductivity.

By introducing the following variables of similarity, we also search similarity solution for Eq. (1)(3) with boundary conditions (4)

$\eta=\left(\frac{(n+1) b}{2 v_{f}}\right)^{1 / 2} y x^{\frac{n-1}{2}}, \psi=\left(\frac{2 b v_{f}}{n+1}\right)^{1 / 2} x^{\frac{n+1}{2}} f(\eta), \theta(\eta)=\frac{T-T_{\infty}}{T_{w}-T_{\infty}}$

where $\eta$ is the variable of similarity and $\psi$ is the function of stream described as $u=\partial \psi / \partial y$ and $v=$ $-\partial \psi / \partial x$, which comply with Eq. (1) identically. Using Eq. (6), Eq. (2)-(3) can be reduced to these ODES

$\frac{1}{(1-\varphi)^{2.5}\left(1-\varphi+\varphi \rho_{C N T} / \rho_{f}\right)} f^{\prime \prime \prime}+f f^{\prime \prime}+\beta\left(1-f^{\prime 2}\right)=0$

$\frac{1}{\operatorname{Pr}} \frac{k_{n f} / k_{f}}{\left[1-\varphi+\varphi\left(\rho C_{p}\right)_{C N T} /\left(\rho C_{p}\right)_{f}\right]} \theta^{\prime \prime}+f \theta^{\prime}=0$

Thus, subject to boundary conditions (4) we have

$f(0)=S, f^{\prime}(0)=\varepsilon, \theta(0)=1$

$f^{\prime}(\eta) \rightarrow 1, \theta(\eta) \rightarrow 0$ as $\eta \rightarrow \infty$

where $\beta=\frac{2 n}{n+1}$ is the nonlinear parameter which varies from 1 to 2 as $n$ grows from unity to infinity, as stated in Malvandi et al., [27], $S$ is suction/injection parameter, $\operatorname{Pr}$ is the Prandtl number and $\varepsilon$ is the stretching/shrinking parameter given by

$S=\frac{-V_{w}}{\left(\frac{b v_{f}(n+1)}{2}\right)^{\frac{1}{2}} x^{\frac{n-1}{2}}}, \operatorname{Pr}=\frac{v_{f}}{\alpha_{f}}, \varepsilon=\frac{a}{b}$

which for stretching is when $\varepsilon>0$ and shrinking is when $\varepsilon<0$, while suction when $S>0$ and injection when $S<0$.

Physical interest's quantities in this research are the coefficient of skin friction $C_{f}$ and the local Nusselt number $N u_{x}$, identified as

$C_{f}=\frac{\tau_{w}}{\rho_{f} U_{\infty}^{2}}, \quad N u_{x}=\frac{x q_{w}}{k_{f}\left(T_{w}-T_{\infty}\right)}$ 
in which the surface shear stress $\tau_{w}$ and the surface heat flux $q_{w}$ are likely given as

$\tau_{w}=\mu_{n f}\left(\frac{\partial u}{\partial y}\right)_{y=0}, \quad q_{w}=-k_{n f}\left(\frac{\partial T}{\partial y}\right)_{y=0}$

with $\mu_{n f}$ is the viscosity of the nanofluids and $k_{n f}$ is the thermal conductivity of the nanofluids. The quantities of physical interest that we acquire following transformation are

$C_{f} R e_{x}^{1 / 2}=\frac{1}{(1-\varphi)^{2.5}} \sqrt{\frac{1}{2-\beta}} f^{\prime \prime}(0)$

$\frac{N u_{x}}{R e_{x}^{\frac{1}{2}}}=-\frac{k_{n f}}{k_{f}} \sqrt{\frac{1}{2-\beta}} \theta^{\prime}(0)$,

where $R e_{x}=U_{\infty} x / v_{f}$ is the local Reynolds number.

\section{Results}

Eq. (7)-(8) are numerically solved by applying the bvp4c package in Matlab, in conjunction with boundary conditions (9). Following to Oztop and Abu-Nada [28], we have acknowledged the selection of $\varphi(0 \leq \varphi \leq 0.2)$, where $\varphi=0$ is regular fluid with $\operatorname{Pr}=6.2$. (water). The thermophysical properties of the base fluid and the CNTs are indexed as in Table 1.

Table 1

Thermophysical properties of CNTs [31]

\begin{tabular}{llll}
\hline Physical properties & Base fluids & Nanoparticle & \\
\cline { 3 - 4 } & & SWCNT & MWCNT \\
\hline$\rho\left(\mathrm{kg} / \mathrm{m}^{3}\right)$ & 997 & 2600 & 1600 \\
$c_{p}(\mathrm{~J} / \mathrm{kgK})$ & 4179 & 425 & 796 \\
$k(\mathrm{~W} / \mathrm{mK}$ & 0.613 & 6600 & 3000 \\
\hline
\end{tabular}

Figure 1 illustrate the $f^{\prime \prime}(0)$ and $-\theta^{\prime}(0)$ graphs for $\varepsilon$ and $\varphi$, where $\varphi=0,0.1$ and 0.2 for waterSWCNTs at $S=0.5$ and $\beta=2$. There exist dual solutions when $\varepsilon_{c}<\varepsilon \leq-1$, unique solution when $\varepsilon>-1$ and no solutions when $\varepsilon<\varepsilon_{c}<0\left(\varepsilon_{c}\right.$ is the critical value). Figure 2 show the $f^{\prime \prime}(0)$ and $-\theta^{\prime}(0)$ graphs for $\varepsilon$ and $S$, where $S=-0.5,0$ and 0.5 for water-SWCNTs when $\beta=1.5$ and $\varphi=$ 0.1 . As parameter $S$ increases, it also increases the skin friction and heat loss from the surface. Hence, the suction slows the separation of the boundary layer while the injection speeds it up. 

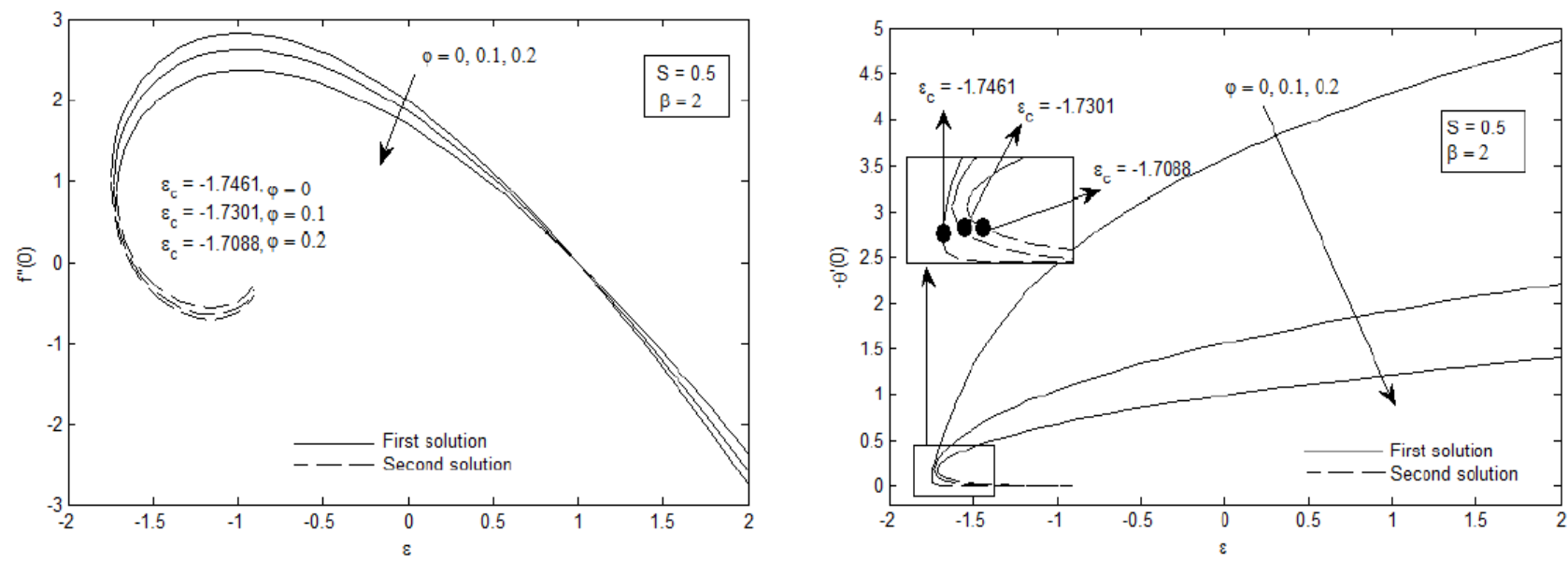

Fig. 1. $f^{\prime \prime}(0)$ and $-\theta^{\prime}(0)$ graphs for $\varphi$ and $\varepsilon$ with water-SWCNTs, respectively
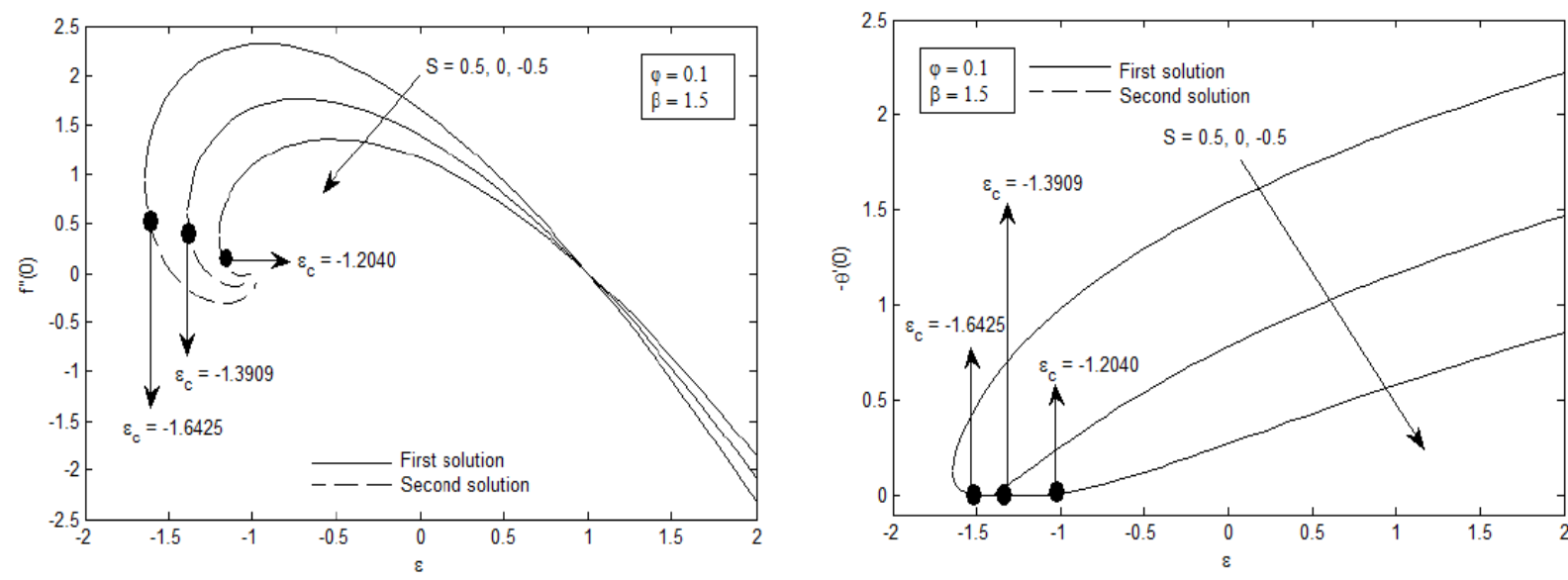

Fig. 2. $f^{\prime \prime}(0)$ and $-\theta^{\prime}(0)$ graphs for $S$ and $\varepsilon$ with water-SWCNTs, respectively

Figure 3 show the $f^{\prime \prime}(0)$ and $-\theta^{\prime}(0)$ graphs for $\varepsilon$ and $\beta$, where $\beta=1,1.5$ and 2 for waterSWCNTs when $S=0.5$ and $\varphi=0.1$. It shows that when $\beta$ increases, the velocity gradients as well as temperature gradients also increases. From both Figure 2 and 3 , we can conclude that parameter $S>0$ (suction) and $\beta$ widen the range of solutions compared to $\varphi$.
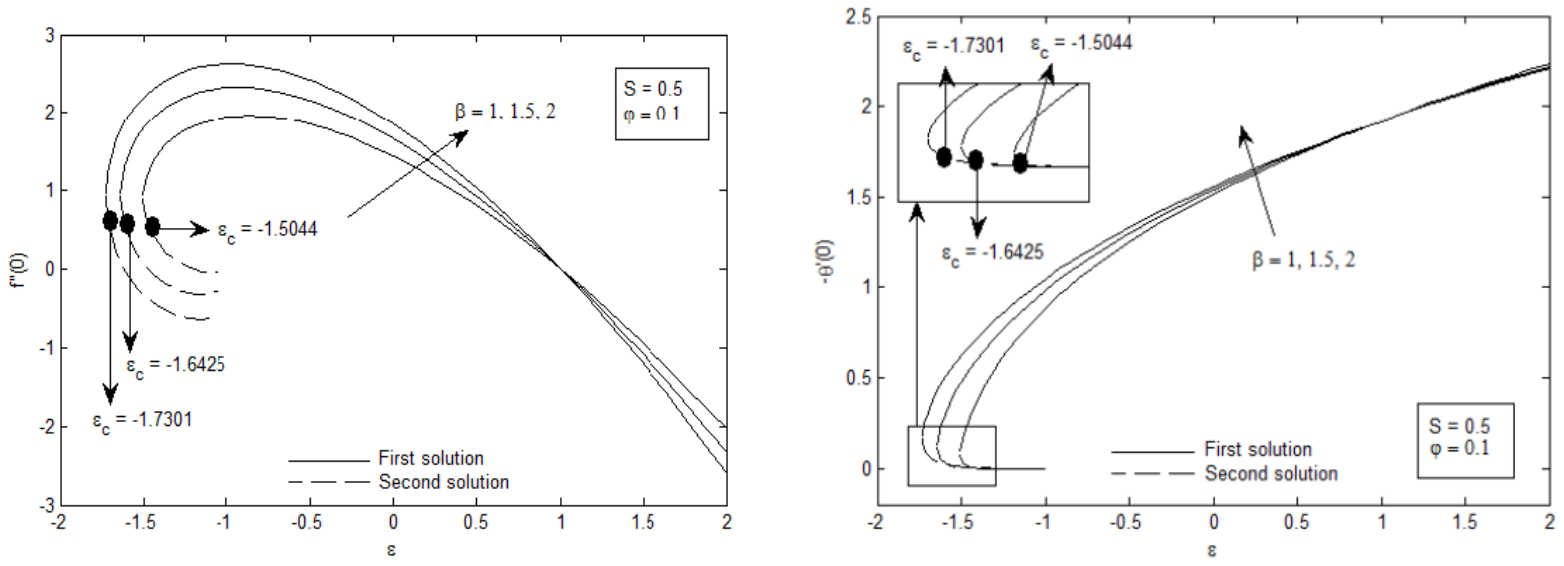

Fig. 3. $f^{\prime \prime}(0)$ and $-\theta^{\prime}(0)$ graphs for $\beta$ and $\varepsilon$ with water-SWCNTs, respectively 
Figure 4 explain the coefficient of skin friction and the local Nusselt number graphs, as per Eq. (13)-(14) for $\varphi$ and $S$ which are $S=-0.5,0$ and 0.5 with $\varepsilon=0.5$ and $\beta=1.5$. It is concluded that, when the $S>0$ (suction) parameter is increasing, the coefficient of skin friction also increasing along with the local Nusselt number. The higher coefficient of skin friction and local Nusselt number are SWCNTs compared to MWCNTs, because their density and thermal conductivity is higher.
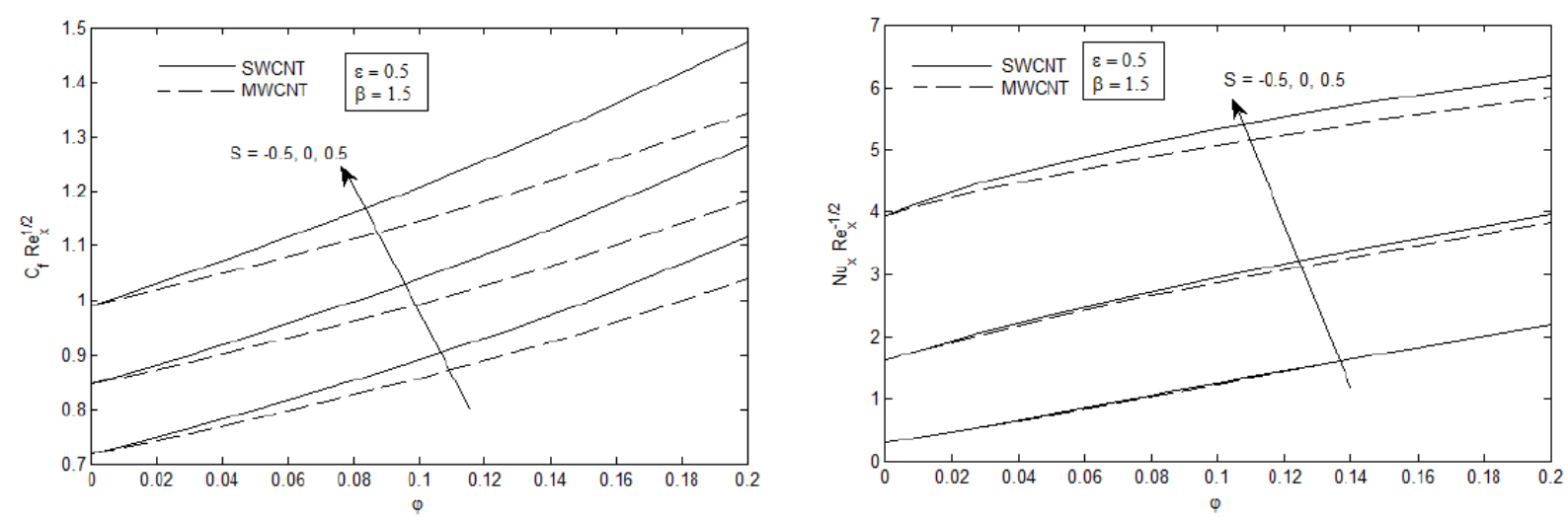

Fig. 4. Coefficient of skin friction and local Nusselt number graphs for $\varphi, S$ and CNTs, respectively

Figure 5-7 show the outcomes of $S, \beta$ and CNTs on the profiles of velocity and temperature, respectively. The term for both first and second solutions applies to the curves shown in Figure 1-3 and asymptotically these profiles follow the boundary conditions (9), which then support the existence of dual solutions shown in Figure 1-3.
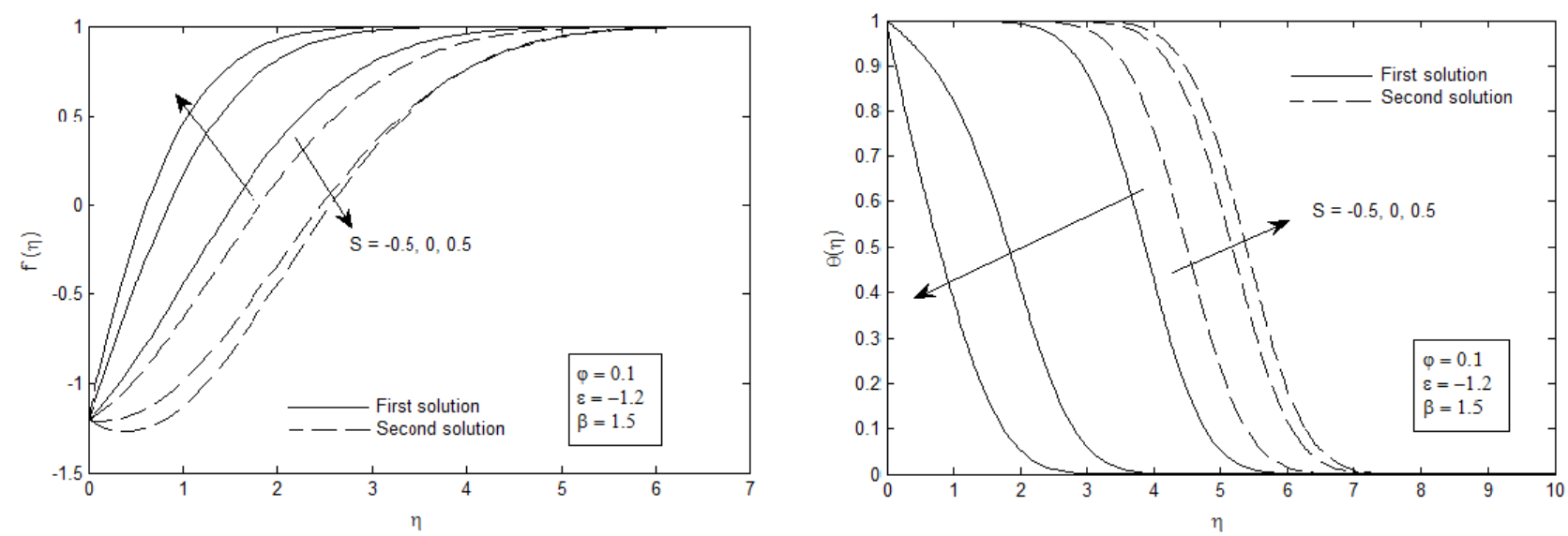

Fig. 5. Profiles of velocity and temperature for $S$ with water-SWCNT, respectively 

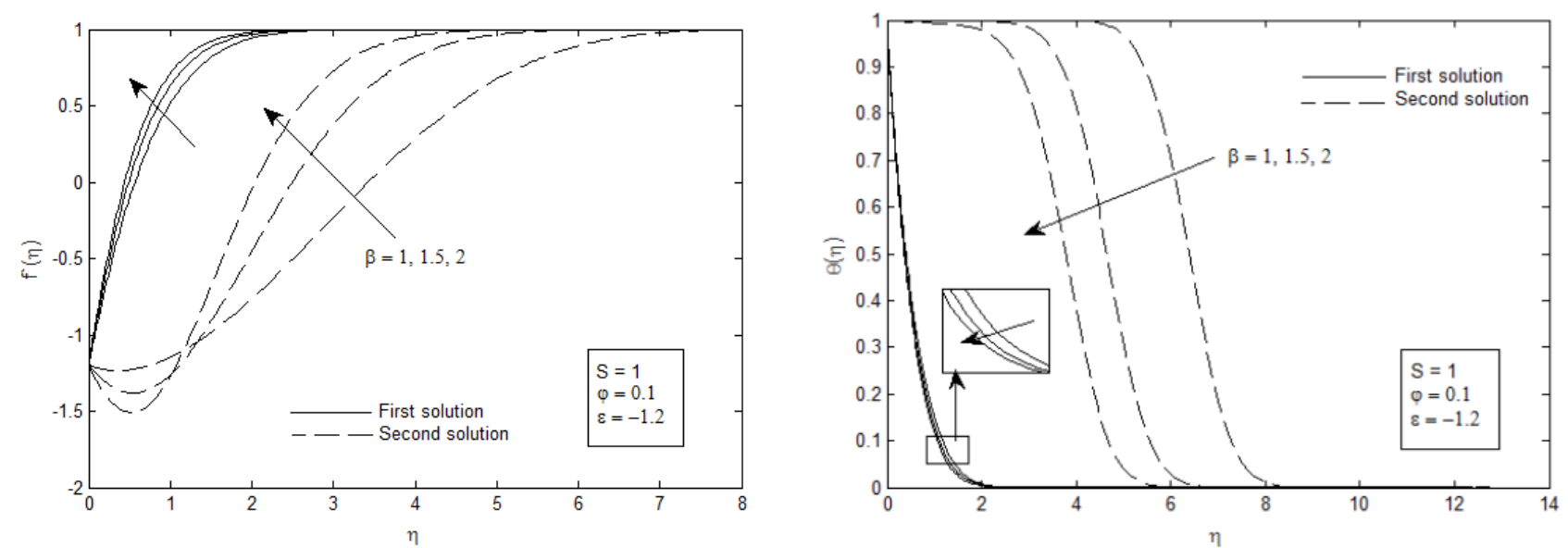

Fig. 6. Profiles of velocity and temperature for $\beta$ with water-SWCNT, respectively
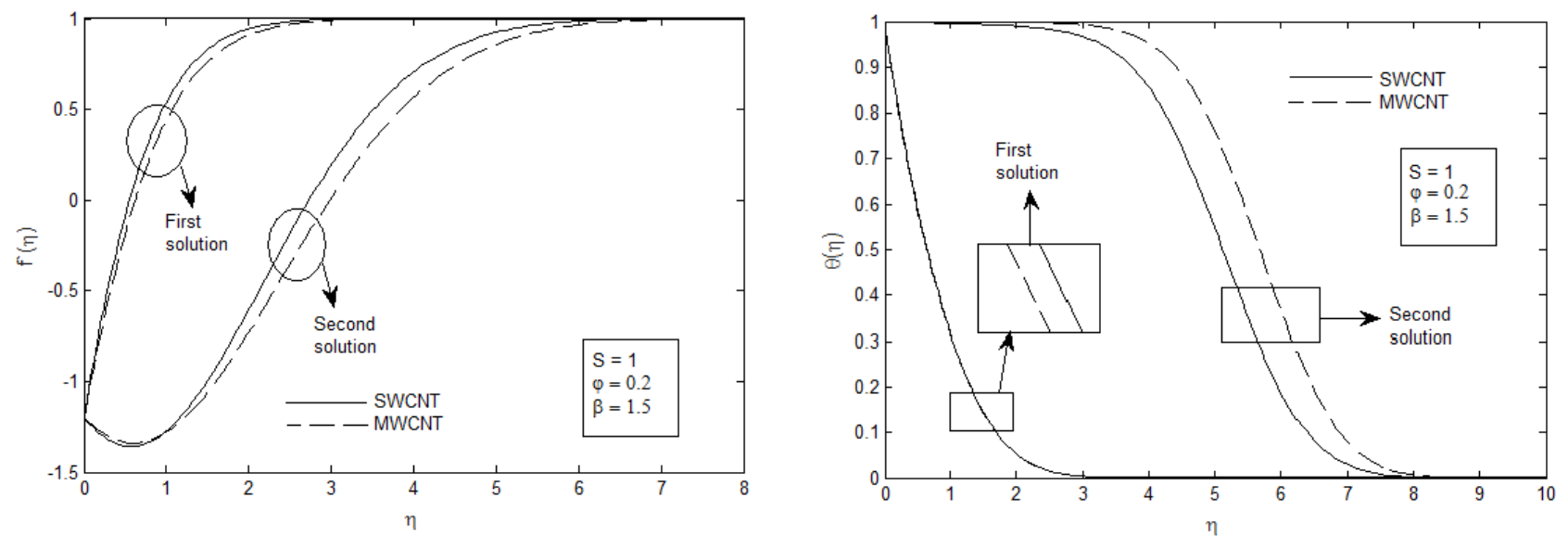

Fig. 7. Profiles of velocity and temperature for CNTs in water base fluid, respectively

\section{Conclusions}

In this paper, we have investigated theoretically and analysed the $\varphi$ and $S$ consequences on the stagnation point flow over a stretching/shrinking sheet. The results indicate that

i. Solutions for a stretching sheet are unique and solutions for a shrinking sheet are dual.

ii. The range of solutions widen with an increase of $S$ as well as $\beta$ parameters.

iii. While, for injection, it decreases the range of solutions.

iv. As $S>0$ (suction) increases, the coefficent of skin friction increases too.

v. The heat transfer also increases with an increase of $S>0$ (suction) parameter.

vi. SWCNTs are more effective than MWCNTs in both skin friction and local Nusselt number.

\section{Acknowledgement}

The writers value the financial support that a research grant scheme has provided (FRGS/1/2018/STG06/UPM/02/4/5540155). Finally, a modest yet sincere gratitude for the honest feedback and suggestions from all reviewers. 


\section{References}

[1] Crane, L. J. "Flow Past a Stretching Plate." Journal of Applied Mathematics and Physics 21, no. 4 (1970): 645-647. https://doi.org/10.1007/BF01587695

[2] Lok, Y. Y., A. Ishak, and I. Pop. "MHD stagnation-point flow towards a shrinking sheet." International Journal of Numerical Methods for Heat \& Fluid Flow (2011).

https://doi.org/10.1108/09615531111095076

[3] Ishak, Anuar, Yian Yian Lok, and Ioan Pop. "Stagnation-point flow over a shrinking sheet in a micropolar fluid." Chemical Engineering Communications 197, no. 11 (2010): 1417-1427. https://doi.org/10.1080/00986441003626169

[4] Bachok, Norfifah, Anuar Ishak, and loan Pop. "Melting heat transfer in boundary layer stagnation-point flow towards a stretching/shrinking sheet." Physics letters A 374, no. 40 (2010): 4075-4079.

https://doi.org/10.1016/j.physleta.2010.08.032

[5] Bachok, Norfifah, Anuar Ishak, and Ioan Pop. "On the stagnation-point flow towards a stretching sheet with homogeneous-heterogeneous reactions effects." Communications in Nonlinear Science and Numerical Simulation 16, no. 11 (2011): 4296-4302. https://doi.org/10.1016/i.cnsns.2011.01.008

[6] Othman, Noor Adila, Nor Azizah Yacob, Norfifah Bachok, Anuar Ishak, and loan Pop. "Mixed convection boundarylayer stagnation point flow past a vertical stretching/shrinking surface in a nanofluid." Applied Thermal Engineering 115 (2017): 1412-1417.

https://doi.org/10.1016/i.applthermaleng.2016.10.159

[7] Bakar, Nor Ashikin Abu, Norfifah Bachok, Norihan Md Arifin, and loan Pop. "Stability analysis on the flow and heat transfer of nanofluid past a stretching/shrinking cylinder with suction effect." Results in Physics 9 (2018): 13351344.

https://doi.org/10.1016/j.rinp.2018.04.056

[8] Vajravelu, K. "Viscous flow over a nonlinearly stretching sheet." Applied mathematics and computation 124, no. 3 (2001): 281-288..

https://doi.org/10.1016/S0096-3003(00)00062-X

[9] Cortell, Rafael. "Viscous flow and heat transfer over a nonlinearly stretching sheet." Applied Mathematics and Computation 184, no. 2 (2007): 864-873. https://doi.org/10.1016/i.amc.2006.06.077

[10] Prasad, K. V., K. Vajravelu, and P. S. Datti. "Mixed convection heat transfer over a non-linear stretching surface with variable fluid properties." International Journal of non-linear Mechanics 45, no. 3 (2010): 320-330. https://doi.org/10.1016/i.ijnonlinmec.2009.12.003

[11] Yazdi, M. H., S. Abdullah, I. Hashim, and K. Sopian. "Slip MHD liquid flow and heat transfer over non-linear permeable stretching surface with chemical reaction." International Journal of Heat and Mass Transfer 54, no. 1516 (2011): 3214-3225. https://doi.org/10.1016/j.ijheatmasstransfer.2011.04.009

[12] Das, K. (2015). Nanofluid flow over a non-linear permeable stretching sheet with partial slip. Journal of the Egyptian mathematical society, 23(2), 451-456. https://doi.org/10.1016/j.joems.2014.06.014

[13] Fauzi, N. F., S. Ahmad, and I. Pop. "Stagnation point flow and heat transfer over a nonlinear shrinking sheet with slip effects." Alexandria Engineering Journal 54, no. 4 (2015): 929-934. https://doi.org/10.1016/i.aej.2015.08.004

[14] Ghosh, Sudipta, Swati Mukhopadhyay, and Kuppalapalle Vajravelu. "Dual solutions of slip flow past a nonlinearly shrinking permeable sheet." Alexandria Engineering Journal 55, no. 2 (2016): 1835-1840. https://doi.org/10.1016/j.aej.2016.04.002

[15] Jahan, Shah, Hamzah Sakidin, Roslinda Nazar, and Ioan Pop. "Flow and heat transfer past a permeable nonlinearly stretching/shrinking sheet in a nanofluid: A revised model with stability analysis." Journal of Molecular Liquids 233 (2017): 211-221. https://doi.org/10.1016/i.molliq.2017.03.013

[16] Seth, G. S., and M. K. Mishra. "Analysis of transient flow of MHD nanofluid past a non-linear stretching sheet considering Navier's slip boundary condition." Advanced Powder Technology 28, no. 2 (2017): 375-384. https://doi.org/10.1016/i.apt.2016.10.008

[17] Hayat, Tasawar, Madiha Rashid, Ahmed Alsaedi, and Bashir Ahmad. "Flow of nanofluid by nonlinear stretching velocity." Results in physics 8 (2018): 1104-1109.

https://doi.org/10.1016/i.rinp.2017.12.014 
[18] Choi, S. U. S., Z. G. Zhang, WLockwoodFE Yu, F. E. Lockwood, and E. A. Grulke. "Anomalous thermal conductivity enhancement in nanotube suspensions." Applied physics letters 79, no. 14 (2001): 2252-2254. https://doi.org/10.1063/1.1408272

[19] Maré, Thierry, Salma Halelfadl, Ousmane Sow, Patrice Estellé, Steven Duret, and Frederic Bazantay. "Comparison of the thermal performances of two nanofluids at low temperature in a plate heat exchanger." Experimental Thermal and Fluid Science 35, no. 8 (2011): 1535-1543. https://doi.org/10.1016/i.expthermflusci.2011.07.004

[20] Liu, M. S., M. C. C. Lin, and I. T. Huang. "I and Wang, CC 2005." Enhancement of Thermal Conductivity With Carbon Nanotube for Nanofluids. International Communications in Heat and Mass Transfer 32: 1202-1210. https://doi.org/10.1016/j.icheatmasstransfer.2005.05.005

[21] Akbar, Noreen Sher, E. N. Maraj, and S. Nadeem. "Copper nanoparticle analysis for peristaltic flow in a curved channel with heat transfer characteristics." The European Physical Journal Plus 129, no. 7 (2014): 149. https://doi.org/10.1016/i.molliq.2014.03.006

[22] Hayat, T., Zakir Hussain, A. Alsaedi, and S. Asghar. "Carbon nanotubes effects in the stagnation point flow towards a nonlinear stretching sheet with variable thickness." Advanced Powder Technology 27, no. 4 (2016): 1677-1688. https://doi.org/10.1016/i.apt.2016.06.001

[23] Imtiaz, Maria, Tasawar Hayat, Ahmed Alsaedi, and Bashir Ahmad. "Convective flow of carbon nanotubes between rotating stretchable disks with thermal radiation effects." International journal of heat and mass transfer 101 (2016): 948-957. https://doi.org/10.1016/j.ijheatmasstransfer.2016.05.114

[24] Hayat, T., Zakir Hussain, A. Alsaedi, and B. Ahmad. "Heterogeneous-homogeneous reactions and melting heat transfer effects in flow with carbon nanotubes." Journal of Molecular Liquids 220 (2016): 200-207. https://doi.org/10.1016/i.molliq.2016.04.012

[25] Hayat, Tasawar, Farwa Haider, Taseer Muhammad, and Ahmed Alsaedi. "Three-dimensional rotating flow of carbon nanotubes with Darcy-Forchheimer porous medium." PLoS One 12, no. 7 (2017): e0179576. https://doi.org/10.1371/journal.pone.0179576

[26] Sreedevi, P., P. Sudarsana Reddy, and Ali J. Chamkha. "Magneto-hydrodynamics heat and mass transfer analysis of single and multi-wall carbon nanotubes over vertical cone with convective boundary condition." International journal of Mechanical sciences 135 (2018): 646-655. https://doi.org/10.1016/i.ijmecsci.2017.12.007

[27] Malvandi, A., F. Hedayati, and D. D. Ganji. "Nanofluid flow on the stagnation point of a permeable non-linearly stretching/shrinking sheet." Alexandria engineering journal 57, no. 4 (2018): 2199-2208. https://doi.org/10.1016/j.aej.2017.08.010

[28] Ahmad, Syakila, Azizah Mohd Rohni, and Ioan Pop. "Blasius and Sakiadis problems in nanofluids." Acta Mechanica 218, no. 3-4 (2011): 195-204. https://doi.org/10.1007/s00707-010-0414-6

[29] Oztop, Hakan F., and Eiyad Abu-Nada. "Numerical study of natural convection in partially heated rectangular enclosures filled with nanofluids." International journal of heat and fluid flow 29, no. 5 (2008): 1326-1336. https://doi.org/10.1016/j.ijheatfluidflow.2008.04.009

[30] Xue, Q. Z. "Model for thermal conductivity of carbon nanotube-based composites." Physica B: Condensed Matter 368, no. 1-4 (2005): 302-307. https://doi.org/10.1016/i.physb.2005.07.024

[31] Khan, W. A., Z. H. Khan, and M. Rahi. "Fluid flow and heat transfer of carbon nanotubes along a flat plate with Navier slip boundary." Applied Nanoscience 4, no. 5 (2014): 633-641. https://doi.org/10.1007/s13204-013-0242-9 